\title{
Personality of mothers of substance-dependent patients
}

This article was published in the following Dove Press journal:

Journal of Multidisciplinary Healthcare

27 April 2010

Number of times this article has been viewed

\author{
David Baron' \\ Samir AbolMagd ${ }^{2}$ \\ Salwa Erfan ${ }^{2}$ \\ Mona El Rakhawy ${ }^{2}$ \\ 'Temple University School \\ of Medicine, Philadelphia, PA, USA; \\ ${ }^{2}$ University of Cairo School of \\ Medicine, Cairo, Egypt
}

Correspondence: David Baron Temple University Episcopal Campus, 100 E Lehigh Ave, Medical Arts Building, Suite 305, Philadelphia, PA 19|25, USA Email dbaron@temple.edu

\begin{abstract}
Drug addicts often come from dysfunctional families. The prevailing view in the literature is that mothers of drug-dependent patients can be characterized by strong emotional bonds and overprotection. Studies suggest that maternal rejection could be a major risk factor of developing drug addiction. This work is a continuation of our previous study of childhood parenting experiences of substance-dependent patients. The aims were to compare the personality profile of mothers of substance-dependent patients and that of mothers of matched control subjects; and to examine the relation between the personality of mothers of addicts, and severity of their offspring's addiction. The study group consisted of 20 mothers of substance-dependent patients and a control group of 35 mothers of non-dependent subjects; mothers of both groups were age matched. Patients were diagnosed according to DSM IV criteria. Personalities of mothers of both groups were assessed using the Minnesota Multiphasic Personality Inventory (MMPI). Substance-dependent patients (sons) were administered the Addiction Severity Index (ASI). The mean scores of the MMPI Scales were higher for mothers of dependent patients compared to mothers of non-dependent subjects. Scores on the depression, hysteria and paranoia scales were significantly higher for mothers of patients $(P=0.03,0.02$, and 0.03 , respectively). There was a significant positive correlation between scores of hysteria, and psychopathic deviance and the ASI ( $P=0.03$ and 0.01 , respectively). There were significant negative correlations between scores of social introversion and the ASI drug/alcohol use status $(P=0.007)$, and family history dimensions $(P=0.003)$. Mothers of substance-dependent patients showed disturbances in aspects of personalities that might be related to initiation of perpetuation of substance dependence.
\end{abstract}

Keywords: substance-dependent patients, personality, mothers

\section{Introduction}

"Tis education forms the common mind; just as the twig is bent, the tree's inclined", wrote Alexander Pope in 1734. This is likely one of the earliest poetic descriptions of a current topic of great interest to psychiatrists and research neuroscientists, namely the impact of early psychosocial factors on subsequent neuronal development and ultimate phenotypic presentation. Michael Meaney and colleagues at McGill University have demonstrated, in an elegant series of experiments in rats, the effect of early maternal grooming of rat pups on stress resilience via hippocampal glucocorticoid receptor expression and activation of nerve growth factor inducible-A. The field of psychiatric epigenetics continues to provide evidence that early mother-offspring interactions can dramatically influence the child's behavior as they age. ${ }^{1}$ The focus of this study is to examine retrospectively the potential relationship between maternal personality characteristics, as measured by the Minnesota Multiphasic Personality

submit your manuscript | www.dovepress.com 
Inventory (MMPI), and drug dependence in their sons. The hypothesis is that certain personality traits in mothers may help predict an at-risk population of their sons for the development of drug dependence. This preliminary work is intended to explore a potential translational aspect of the work of Meaney and others.

Bucknall and Robertson, ${ }^{2}$ have demonstrated the role of family in the etiology of drug abuse, with an even greater role in the maintenance of an individual's drug dependence. Andersson and Eisemann, ${ }^{3}$ confirmed that a parental rearing behavior perceived both as rejecting and overprotective represents a link between dysfunctional parenting and the development of maladaptive psychosocial behaviors, like drug addiction.

Drug addicts often come from families where there is frequently expressed ill will and hostility in the home. They have weaker family ties than do those who do not take drugs. In families in which there was contact with drugs, authority belonged to the mother to a greater degree than the father. ${ }^{4}$

Handlarz et $\mathrm{al}^{5}$ studied drug addicts and their families and observed general characteristics common to all substance-dependent patients. Among these were vulnerability of personality and ego weakness, absent father, narcissistic mother, disaggregation of the family, and pathological communication among family members.

Graeven and Schaef ${ }^{6}$ reported the relationship with the opposite sex parent had the strongest impact on both male and female heroin users.

Kaufamn ${ }^{7}$ studied the family structure of drug addicts and their families who were in residential treatment at the time of the study. The most common familial pattern seen was that of a mother enmeshed with her addicted son. The father reported feeling excluded by the dyad and reacted with disengagement, brutality, or increased consumption of alcohol.

This paper examines the personality of mothers and its relationship to severity of addiction of their sons. It is a follow up to our previous work on childhood parenting styles of the substance-dependent patient. ${ }^{8}$

\section{Subjects and method}

The study cohort consisted of 20 mothers of substance-dependent patients. Patients were diagnosed according to Diagnostic Statistical Manual (DSM IV). ${ }^{9}$ The control group consisted of 35 mothers of non-drug-dependent subjects. Mothers from both groups fulfilled the following inclusion criteria:

- Age between 40 and 60 .

- Not suffering substance use disorders or any other psychiatric disorders.

- Not suffering significant medical disorder.
All study subjects were informed they were participating in a volunteer study examining the relationship between a mother's personality and drug dependence in their children. All study participants provided informed consent to a psychiatrist (SA) member of the study team. Both groups were administered the Minnesota Multiphasic Personality Inventory (MMPI), ${ }^{10}$ which is a self-reported inventory developed in 1937 by Starke Hanthaway and Charnley McKinley. The MMPI gives scores on 10 standard clinical scales. The items of each scale were selected for their ability to separate medical and psychiatric patients from normal control subjects. We applied the Arabic version prepared by Melika et al. ${ }^{10}$

Substance-dependent patients were assessed with the Addiction Severity Index (ASI). ${ }^{11}$ The ASI is a semi-structured interview designed to address 7 potential problem areas in substance use disorder patients: medical status, employment and support, drug use, alcohol use, legal status, family/social status, and psychiatric status. In 1 hour, a skilled interviewer can gather information on recent (past 30 days) and lifetime problems in all of the problem areas. The ASI provided an overview of problems related to substance, rather than focusing on any single area.

Personality profiles of mothers of both groups were compared, and those of mothers of dependent patients were correlated to the 7 dimensions of the ASI.

\section{Statistical analysis}

The data were coded and entered on PC using the statistical package SPSS 15.0. The study variables were summarized and described using the mean and SD. Differences between quantitative variables for the addicts group and the control group were assessed using Student's t-test. The MMPI scales for mothers were classified into risk grades and differences between the study groups were assessed using Pearson's chi-square test. The association between the different study scales for mother and their offspring was assessed using correlation analysis. The level of significance for the performed tests was at $P<0.05$.

\section{Results}

Mean age of patient was 27.5 years. Mean age at onset was 19.4 years. The mean age of mothers of patients was 50 , while that of the control was 44.8 years. They were age matched $(P=0.07)$

There were significant differences between both groups on depression, hysteria, and paranoia scales of the MMPI. Depression scores were higher than 70 (pathological) in 
$8 \%$ of study group compared to only $1 \%$ of control group. Depression scores were in the normal range (45 to 50) in $5 \%$ of study group compared to $22 \%$ of the control group $(P=0.003)$. Scores on the hysteria scale were higher than 70 in $4 \%$ of study group compared to none of the control group. Negative scores for hysteria were seen in $15 \%$ of the study group, compared to $40 \%$ of the control group $(P=0.02)$. Paranoia scale scores were positive in $4 \%$ of the study group, compared to $1 \%$ of controls $(P=0.03)$. No paranoia was detected in $10 \%$ of the study group, compared to $40 \%$ of controls. No significant differences were reported on any of the other MMPI scales (Table 1).

Significant positive correlations were observed among mothers of substance-dependent patients on scores of depression, hypochondrias, and psychopathic deviance $(P=0.003$, and $P=0.01$ respectively). A positive correlation was also detected between scores of hysteria, hypochondrias and psychopathic deviance ( $P=0.001$ and $P=0.004$, respectively), and between paranoia and hypochondrias, depression, and psychopathic deviance $(P=0.005, P=0.01$, and $P=0.01$, respectively).

Pearson's correlation coefficient was calculated to measure the degree of association between MMPI scores and the ASI. Results showed significant positive correlation between scores of hysteria and psychopathic deviance and ASI legal status impairment $(P=0.023$ and $P=0.019$, respectively). There was a significant negative correlation between social introversion and ASI scores of drug/ alcohol use, and family history $(P=0.007$ and $P=0.003$, respectively). No other significant differences were reported (Table 2). Significant positive correlations were observed between scores of social status impairment and those of psychiatric and legal status impairment $(P=0.005$ and $P=0.04$, respectively).

\section{Discussion}

The role of parenting in the development of drug abuse is a widely discussed topic. This is best demonstrated by 2,590,000 Google hits displayed when "the role of parenting on drug abuse" is searched. Behavioral scientists appreciated the highly complex nature of parental interactions, particularly maternal, and have demonstrated the role of nurturing in early life to the development of pathophysiologic functioning in later years of the offspring. Schweitzer and Lawton ${ }^{12}$ and Brook et $\mathrm{al}^{1}$ have independently reported mothers assessed as cold, indifferent, controlling, and intrusive were a major risk factor for the development of adolescent drug use. Similarly, Andersson and Eisemann ${ }^{3}$ reported that parenting perceived as rejecting was linked to maladaptive psychosocial behaviors, including drug abuse. Our previous study confirmed these findings ${ }^{8}$ and demonstrated that substance-abusing patients had lower maternal protection scores than non-drug-abusing controls. There was also a significant negative correlation between paternal care and ASI scores. This analysis of maternal MMPI scores in addicted offspring demonstrated a statistically significant correlation in the depression, hysteria and paranoia subscales.

These results have significant health, mental health, and public health and health policy implications. The cost of drug abuse and addiction to the patient, their family, and society is enormous.

Any primary interventions which might decrease pathologic drug use would be beneficial. These and other data strongly support the importance of early mother-child assessment and intervention when clinically indicated.

Table I Comparison between Minnesota Multiphasic Personality Inventory (MMPI) scores of patient's mothers and control

\begin{tabular}{|c|c|c|c|c|c|c|c|c|c|c|c|c|c|c|c|c|c|}
\hline & \multicolumn{8}{|c|}{ Patient mothers (No. = 20) } & \multicolumn{8}{|c|}{ Control mothers $($ No. = 35) } & \multirow[t]{3}{*}{ Significance } \\
\hline & \multicolumn{2}{|l|}{$<45$} & \multicolumn{2}{|c|}{$45-55$} & \multicolumn{2}{|c|}{$55-70$} & \multicolumn{2}{|l|}{$>70$} & \multicolumn{2}{|l|}{$<45$} & \multicolumn{2}{|c|}{$45-55$} & \multicolumn{2}{|c|}{$55-70$} & \multicolumn{2}{|l|}{$>70$} & \\
\hline & No. & $\%$ & No. & $\%$ & No. & $\%$ & No. & $\%$ & No. & $\%$ & No. & $\%$ & No. & $\%$ & No. & $\%$ & \\
\hline Hypochondriasis & 2 & 10 & 8 & 40 & 9 & 45 & I & 5 & 7 & 20 & 12 & 34 & 15 & 42.9 & 1 & 2.9 & 0.785 \\
\hline Depression & 2 & 10 & 1 & 5 & 9 & 45 & 8 & 40 & 6 & 17.1 & 8 & 22.9 & 20 & 57 & I & 2.9 & 0.003 \\
\hline Hysteria & 4 & 20 & 3 & 15 & 9 & 45 & 4 & 20 & 6 & I7.1 & 14 & 40 & 15 & 42.9 & 0 & 0 & 0.022 \\
\hline Psychopathic deviance & 6 & 30 & 3 & 15 & 10 & 50 & $\mathrm{I}$ & 5 & 14 & 40 & 10 & 28.6 & II & 31.4 & 0 & 0 & 0.237 \\
\hline Masculinity-femininity & 4 & 20 & 8 & 40 & 8 & 40 & - & - & 5 & 14.3 & 13 & 37.1 & 17 & 48.6 & - & - & 0.784 \\
\hline Paranoia & 5 & 25 & 2 & 10 & 9 & 45 & 4 & 20 & 6 & 17. & 14 & 40 & 14 & 40 & I & 2.9 & 0.036 \\
\hline Psychasthenia & 4 & 20 & II & 55 & 5 & 15 & - & - & 16 & 45.7 & 15 & 42.9 & 4 & II.4 & - & - & 0.126 \\
\hline Schizophrenia & 6 & 30 & 5 & 25 & 7 & 35 & 2 & 10 & 15 & 42.9 & II & 31.4 & 9 & 25.7 & 0 & 0 & 0.203 \\
\hline Hypomania & 10 & 50 & 4 & 20 & 6 & 30 & - & - & 18 & 51.4 & 12 & 43.3 & 5 & 14.3 & - & - & 0.291 \\
\hline Social introversion & 4 & 20 & 5 & 25 & II & 55 & - & - & 3 & 8.6 & 15 & 42.9 & 17 & 48.6 & - & - & 0.283 \\
\hline
\end{tabular}


Table 2 Correlation between mother's Minnesota Multiphasic Personality Inventory (MMPI) scores and Addiction Severity Index (ASI)

\begin{tabular}{|c|c|c|c|c|c|c|c|c|}
\hline MMPI & ASI & $\begin{array}{l}\text { Medical } \\
\text { status }\end{array}$ & $\begin{array}{l}\text { Employment/ } \\
\text { support status }\end{array}$ & $\begin{array}{l}\text { Drug/alcohol } \\
\text { use }\end{array}$ & $\begin{array}{l}\text { Legal } \\
\text { status }\end{array}$ & $\begin{array}{l}\text { Family/social } \\
\text { relation }\end{array}$ & $\begin{array}{l}\text { Family } \\
\text { history }\end{array}$ & $\begin{array}{l}\text { Psychiatric } \\
\text { status }\end{array}$ \\
\hline \multirow[t]{2}{*}{ Hypochondriasis } & Pearson's correlation & -0.043 & -0.103 & -0.188 & 0.171 & 0.095 & -0.016 & -0.258 \\
\hline & sig. (2-tailed) & 0.857 & 0.667 & 0.427 & 0.471 & 0.689 & 0.946 & 0.272 \\
\hline \multirow[t]{2}{*}{ Depression } & Pearson's correlation & -0.010 & 0.038 & -0.277 & 0.192 & 0.196 & -0.388 & -0.190 \\
\hline & sig. (2-tailed) & 0.967 & 0.875 & 0.237 & 0.418 & 0.409 & 0.091 & 0.422 \\
\hline \multirow[t]{2}{*}{ Hysteria } & Pearson's correlation & -0.088 & 0.099 & -0.060 & 0.507 & 0.224 & 0.076 & 0.109 \\
\hline & sig. (2-tailed) & 0.711 & 0.679 & 0.801 & 0.023 & 0.343 & 0.751 & 0.648 \\
\hline Psychopathic & Pearson's correlation & 0.079 & 0.016 & -0.073 & 0.519 & 0.240 & -0.197 & -0.084 \\
\hline deviance & sig. (2-tailed) & $0.74 I$ & 0.946 & 0.758 & 0.019 & 0.308 & 0.404 & 0.723 \\
\hline Masculinity- & Pearson's correlation & 0.130 & -0.153 & -0.224 & 0.234 & 0.010 & -0.195 & -0.379 \\
\hline femininity & sig. (2-tailed) & 0.584 & 0.521 & 0.342 & 0.321 & 0.967 & 0.410 & 0.099 \\
\hline \multirow[t]{2}{*}{ Paranoia } & Pearson's correlation & -0.028 & 0.057 & -0.129 & 0.199 & 0.199 & -0.059 & -0.080 \\
\hline & sig. (2-tailed) & 0.906 & 0.812 & 0.589 & 0.401 & 0.401 & 0.805 & 0.736 \\
\hline \multirow[t]{2}{*}{ Psychasthenia } & Pearson's correlation & 0.043 & -0.247 & -0.104 & 0.217 & 0.143 & -0.171 & -0.137 \\
\hline & sig. (2-tailed) & 0.857 & 0.293 & 0.664 & 0.358 & 0.547 & 0.472 & 0.563 \\
\hline \multirow[t]{2}{*}{ Schizophrenia } & Pearson's correlation & -0.146 & -0.199 & -0.017 & 0.029 & 0.040 & -0.038 & -0.167 \\
\hline & sig. (2-tailed) & 0.538 & 0.401 & 0.944 & 0.903 & 0.868 & 0.875 & 0.481 \\
\hline \multirow[t]{2}{*}{ Hypomania } & Pearson's correlation & 0.023 & 0.075 & -0.203 & 0.203 & 0.166 & -0.115 & -0.082 \\
\hline & sig. (2-tailed) & 0.922 & 0.753 & 0.391 & 0.391 & 0.484 & 0.629 & 0.732 \\
\hline \multirow[t]{2}{*}{ Social introversion } & Pearson's correlation & -0.301 & -0.325 & -0.582 & -0.029 & 0.013 & -0.622 & -0.391 \\
\hline & sig. (2-tailed) & 0.197 & 0.120 & 0.007 & 0.904 & 0.957 & 0.003 & 0.088 \\
\hline
\end{tabular}

Although the role of family varies somewhat based on cultural norms, the effect of early maternal nurturing on neuronal development and subsequent phenotypic expression is not affected by socio-cultural variations. It is far more effective to work with mothers than to treat drug addiction in their grown children.

Future research needs to focus on identifying cost-effective and clinically effective early intervention strategies through prospective, longitudinal trials. Clinical translational research drawing on results from pre-clinical reports will also be valuable.

\section{Disclosures}

The authors disclose no conflicts of interest.

\section{References}

1. Brook JS, Brook DW, Whiteman M. Maternal correlates of toddler insecure and dependent behavior. J Genet Psychol. 2003;164(1):72.

2. Bucknall AB, Robertson JR. Heroin misuse and family medicine. Fam Pract. 1985;2(4):244-251.

Journal of Multidisciplinary Healthcare

\section{Publish your work in this journal}

The Journal of Multidisciplinary Healthcare is an international, peerreviewed open-access journal that aims to represent and publish research in healthcare areas delivered by practitioners of different disciplines. This includes studies and reviews conducted by multidisciplinary teams as well as research which evaluates the results or conduct of such teams or
3. Andersson P, Eisemann M. Parental rearing and individual vulnerability to drug addiction: a controlled study in a Swedish sample. Nord J Psychiatry. 2003;57(2):147-156.

4. Jedrzejczak M. Family and environmental factors of drug addiction among young recruits. Mil Med. 2005;170(8):688-690.

5. Handlarz MC, De Schmer MC, Waingortin D, Cervone N, Farias MA. Study and treatment of the drug addict and his family. Acta Psiquiatr Psicol Am Lat. 1979;22(4):289-294.

6. Graeven DB, Schaef RD. Family life and levels of involvement in an dolescent heroin epidemic. Int J Addict. 1978;13(5):747-771.

7. Kaufman E. Family structures of narcotic addicts. Int $J$ Addict. 1981;16(2):273-282.

8. Erfan S. Childhood parenting experiences in substance dependent patents: A controlled Study. Curr Psychiatr. 2004;11(3):405-413.

9. American Psychiatric Association. Diagnostic and Statistical Manual and Mental of Mental Disorders. 4th ed. Washington, DC: American Psychiatric Press; 1994.

10. Hathaway SR, McKinley JC. A multiphasic personality schedule (Minnesota): I. Construction of the schedule. Journal of Psychology. 1940;10:249-254. Translated into Arabic by: Melika L, Hana A, Ismail M. Arabic translation of Minnesota Multiphasic Personality Inventory (MMPI), Cairo: The Psychological Corporation; 1943.

11. McLellan AT, Kushner H, Metzger D, Peters F, et al. The 5th edition of the ASI. J Subst Abuse Treat. 1992;9:199-213.

12. Schweitzer RD, Lawton PA. Drug abusers' perceptions of their parents. Br J Addict. 1993;84(3):309-314.

\section{Dovepress}

healthcare processes in general. The journal covers a wide range of areas and welcomes submission from practitioners at all levels, from all over the world. The manuscript management system is completely online and includes a very quick and fair peer-review system. Visit http://www.dovepress.com/testimonials.php to read real quotes from published authors. 